\title{
Nutritional impacts of a fruit and vegetable subsidy programme for disadvantaged Australian Aboriginal children
}

\author{
Andrew P. Black ${ }^{1,2 *}$, Hassan Vally ${ }^{3}$, Peter Morris ${ }^{4}$, Mark Daniel ${ }^{5,6}$, Adrian Esterman ${ }^{7}$, \\ Connie S. Karschimkus ${ }^{6,8}$ and Kerin O'Dea ${ }^{1}$ \\ ${ }^{1}$ Division of Health Sciences, Sansom Institute for Health Research, University of South Australia, Adelaide, SA, Australia \\ ${ }^{2}$ Bulgarr Ngaru Medical Aboriginal Corporation, PO Box 1256, Grafton, NSW 2460, Australia \\ ${ }^{3}$ School of Public Health and Human Biosciences, La Trobe University, Melbourne, VIC, Australia \\ ${ }^{4}$ Menzies School of Health Research, Charles Darwin University, Darwin, NT, Australia \\ ${ }^{5}$ Social Epidemiology and Evaluation Research Unit, School of Population Health, University of South Australia, \\ Adelaide, SA 5001, Australia \\ ${ }^{6}$ Department of Medicine, St Vincent's Hospital, The University of Melbourne, Fitzroy, VIC 3065, Australia \\ ${ }^{7}$ Division of Health Sciences, School of Nursing and Midwifery, University of South Australia, Adelaide, SA, Australia \\ ${ }^{8}$ Western Health, Victorian Department of Health, Melbourne, VIC, Australia
}

(Submitted 7 January 2013 - Final revision received 30 April 2013 - Accepted 1 May 2013 - First published online 7 June 2013)

\section{Abstract}

Healthy food subsidy programmes have not been widely implemented in high-income countries apart from the USA and the UK. There is, however, interest being expressed in the potential of healthy food subsidies to complement nutrition promotion initiatives and reduce the social disparities in healthy eating. Herein, we describe the impact of a fruit and vegetable (F\&V) subsidy programme on the nutritional status of a cohort of disadvantaged Aboriginal children living in rural Australia. A before-and-after study was used to assess the nutritional impact in 174 children whose families received weekly boxes of subsidised F\&V organised through three Aboriginal medical services. The nutritional impact was assessed by comparing $24 \mathrm{~h}$ dietary recalls and plasma carotenoid and vitamin $\mathrm{C}$ levels at baseline and after 12 months. A general linear model was used to assess the changes in biomarker levels and dietary intake, controlled for age, sex, community and baseline levels. Baseline assessment in 149 children showed low F\&V consumption. Significant increases $(P<0 \cdot 05)$ in $\beta$-cryptoxanthin (28.9 nmol/1, 18\%), vitamin C (10.1 $\mu \mathrm{mol} / 1,21 \%)$ and lutein-zeaxanthin (39.3 nmol/1, $11 \%)$ levels were observed at the 12 -month follow-up in 115 children, although the self-reported F\&V intake was unchanged. The improvements in the levels of biomarkers of F\&V intake demonstrated in the present study are consistent with increased F\&V intake. Such dietary improvements, if sustained, could reduce non-communicable disease rates. A controlled study of healthy food subsidies, together with an economic analysis, would facilitate a thorough assessment of the costs and benefits of subsidising healthy foods for disadvantaged Aboriginal Australians.

Key words: Fruit and vegetables: Subsidy programmes: Nutrition: Aboriginal children

Higher intake of fruit and vegetables (F\&V) reduces the risk of chronic diseases including $\mathrm{CVD}^{(1,2)}$, diabetes ${ }^{(3)}$, stroke $^{(4,5)}$ and cancer $^{(6)}$. It is also linked to a lower risk of obesity ${ }^{(7)}$ and hypertension $^{(8)}$. Despite this, low F\&V intake is common in many countries ${ }^{(9)}$. Among high-income countries, low F\&V consumption is more prevalent in those of lower socio-economic status ${ }^{(10-12)}$. Successful strategies to increase F\&V intake offer the potential to reduce the economic costs and prevalence of chronic diseases. Strategies that are effective in those of low socio-economic status have the potential to also reduce health inequalities.
Extensive health promotion campaigns to promote $\mathrm{F} \& \mathrm{~V}$ consumption have not been sufficient to reduce the high prevalence of less healthy dietary patterns ${ }^{(13)}$. Pricing strategies, including both taxation of less healthy foods and price discounts or subsidies for healthier foods, have been proposed as alternative strategies that could complement health promotion ${ }^{(14)}$. Economic modelling consistently indicates that price subsidies for healthy foods are likely to produce significant improvements in healthy food consumption, including F\&V consumption ${ }^{(15,16)}$, particularly in those on low incomes ${ }^{(17,18)}$. In the USA and the UK, where long-standing

Abbreviations: F\&V, fruit and vegetables; RCT, randomised controlled trial.

*Corresponding author: Dr A. P. Black, fax +612 66432202, email ablack@bulgarr.com.au 
food subsidy programmes are important components of social security for low-income families, there have been recent changes made to some of these programmes to better promote the consumption of F\&V. Despite the large investment in food subsidy programmes, particularly in the USA, there is limited high-quality evidence of their effectiveness ${ }^{(19)}$. A $12.5 \%$ price discount, but not tailored nutrition education, increased healthy food purchases by $11 \%$ in one randomised controlled trial (RCT) in a supermarket setting ${ }^{(20)}$. Another RCT, currently underway, will enhance these findings by comparing skill building for healthy eating with or without price discounts ${ }^{(21)}$.

In Australia, Aboriginal and Torres Strait Islander people have poorer health outcomes and are more likely to be of lower socio-economic status than the general population ${ }^{(22)}$. Pricing strategies to promote healthy nutrition have not been widely implemented in Australia, either among Indigenous Australians or among those with low incomes. In this context, the present study reports on a F\&V subsidy programme instituted at three rural Aboriginal community-controlled health services. The programme was initially instituted in 2005 at one service in response to poor nutrition among lowincome families visiting the health service. The aims of the programme were to improve nutritional intake and engage participants in preventive health activities.

The aim of the present study was to evaluate whether participation in this F\&V subsidy programme for 12 months was associated with changes in nutritional biomarker levels and dietary behaviour in a cohort of Aboriginal children.

\section{Subjects and methods}

\section{The fruit and vegetable subsidy programme}

A F\&V subsidy programme was established by the Bulgarr Ngaru Medical Aboriginal Corporation for the Aboriginal communities in rural towns in the Clarence Valley in New South Wales, Australia, in 2005. The health service invited lowincome Aboriginal families with one or more young children to join the programme, which combined annual health assessments, including dental and hearing check-ups, with weekly receipt of a box of subsidised F\&V. The boxes of seasonal F\&V were organised by local F\&V shops in each community at a family's request. Each family paid five dollars for a box containing $\$ 40$ worth of $\mathrm{F} \& \mathrm{~V}$ (or $\$ 60$ if five or more children in the household) and collected the box from the F\&V shop. The F\&V boxes contained a selection of commonly available $\mathrm{F} \& \mathrm{~V}$ (with more vegetables than fruit) chosen by the $\mathrm{F} \& \mathrm{~V}$ shops based on value for money and availability (see Supplementary file 1 (available online) for a list of options provided to guide the F\&V shop staff). Families could exchange some unwanted F\&V for alternative F\&V. The programme was developed after the success of a nutrition programme in a remote Aboriginal community school in the Clarence Valley, described elsewhere ${ }^{(23,24)}$.

This is an ongoing programme in the Clarence Valley; however, this evaluation study involved all new families who joined the programme at this time. At baseline (before receiving $\mathrm{F} \& \mathrm{~V}$ ) and after 12 months, all children in these families underwent assessments of dietary intake and nutritional status specifically as part of the evaluation. The recruitment and baseline assessments were undertaken between December 2008 and September 2009, with followup assessments being completed between December 2009 and September 2010.

Additional funding enabled the Galambila Aboriginal Health Service in Coffs Harbour and the Giingan Darrunday Marlaanggu Health Clinic in the Nambucca Valley to institute similar F\&V subsidy programmes for the duration of this evaluation study. These health services decided to participate in this evaluation study, and all families at these locations participated in the nutritional status assessments for this evaluation. Although the demographics and health status are similar in each of these Aboriginal communities, the availability of and arrangements with the F\&V shops varied in the communities. In Coffs Harbour, families received vouchers from the health service, which they redeemed at the F\&V shop by selecting their own F\&V. In the Nambucca Valley, the F\&V shop was in a different town, hence the health service staff collected and delivered the boxes of F\&V to families at their homes and collected the $\$ 5$ contribution from them.

Nutrition promotion complemented the F\&V boxes with seasonal recipe and practical cooking and nutrition education sessions conducted by dietitians (in the Clarence Valley and the Nambucca Valley) or trained nutrition health workers (in Coffs Harbour). There were three or four of these sessions conducted over 12 months in each of the towns in the Clarence Valley, although attending the sessions was not mandatory and less than half of the participating families attended the sessions. There were five sessions conducted over 5 weeks in the Nambucca Valley, which were well attended. No group education occurred in Coffs Harbour; however, individual families were given nutrition education after the children's $24 \mathrm{~h}$ dietary recalls by the nutrition health workers. Simple seasonal recipes were shared between sites, although the content of nutrition education was determined by the local staff.

\section{Participants}

The participants were low-income Aboriginal families (predominantly unemployed or receiving pensions) with one or more children aged $\leq 17$ years (at commencement). Many of the children had identified nutrition risk (e.g. underweight or overweight and chronic or recurrent infections) or presented frequently with episodes of illness to the health service. Parents/carers provided consent and agreed for their children to undergo annual health assessments including the research evaluation assessments.

\section{Data collection and laboratory methods}

As part of the annual health assessments, each child's nutritional status was assessed with a $24 \mathrm{~h}$ dietary recall and a blood test before and after 12 months on the programme. These assessments were completed as close to 1 year apart as possible to minimise seasonal variation. Blood samples 
were analysed for carotenoid, vitamin A, vitamin E, vitamin C, lipid and C-reactive protein levels. Individual results were discussed with the participant/carer at follow-up appointments, and overall summary results were presented in a non-technical language to the communities during focus groups.

The $24 \mathrm{~h}$ dietary recalls were completed by the participants face to face with a dietitian or a trained Aboriginal health worker. For participants aged $<10$ years, these were completed together with a parent/carer. Data collection was undertaken by following the multi-pass method described in the 1995 Australian National Nutrition Survey ${ }^{(25)}$. In addition, the participants were asked about their usual consumption of F\&V using validated short dietary questions based on the Dietary Intake Assessment Tool developed in Queensland, Australia $^{(26)}$. Short dietary questions have been developed for use in children's dietary surveys ${ }^{(26)}$ and were used in the present study to contrast with the estimates of self-reported $\mathrm{F} \& \mathrm{~V}$ intake from the $24 \mathrm{~h}$ recalls.

Non-fasting venous blood samples were collected by clinical staff into tubes wrapped in a foil and stored on ice before transport to a local pathology laboratory. In the laboratory, they were separated, and plasma samples for the measurement of carotenoid, vitamin A and vitamin E levels were frozen at $-20^{\circ} \mathrm{C}$. The frozen plasma samples were transported on dry ice and stored at $-80^{\circ} \mathrm{C}$ before analysis. The samples were protected from light throughout processing to prevent carotenoid degradation.

Blood samples were analysed for the levels of lipids and C-reactive protein at either Grafton Hospital Pathology, on a Cobas Integra 800 chemistry analyser (Roche Diagnostics), or Symbion Laverty Pathology, Coffs Harbour, on a Cobas Integra 400 chemistry analyser (Roche Diagnostics). Frozen plasma samples were transported on dry ice to Royal Prince Alfred Hospital, Sydney, and were analysed for vitamin C level using HPLC with electrochemical detection. Due to logistical problems, samples for the measurement of vitamin $\mathrm{C}$ level were not obtained at baseline in Coffs Harbour or the Nambucca Valley.

The levels of carotenoids, retinol and tocopherols were analysed using HPLC, as described by Su et al. ${ }^{(27)}$ with minor changes. Briefly, after extraction and drying, $50 \mu \mathrm{l}$ of a plasma mixture were analysed using HPLC (Shimadzu HPLC machine equipped with an SPD-M20A PDA detector and a NovoPak $\mathrm{C}^{18}$ column; Shimadzu Corporation) with the detection of absorbance at $292 \mathrm{~nm}$ for tocopherols, $325 \mathrm{~nm}$ for retinol and $450 \mathrm{~nm}$ for carotenoids. The samples were assayed using standardised techniques by laboratory staff who were unaware of the study design.

The dietary recall data were analysed using the FoodWorks Professional 2009 dietary software programme (Xyris) using the AusNut 2007 Australian food database. Data entry and analysis were completed by a post-graduate dietetics student with input from an experienced dietetics researcher.

\section{Statistical analysis}

The analysis sought to answer the question of whether the $\mathrm{F} \& \mathrm{~V}$ programme was associated with changes in biomarker levels and dietary behaviour, and the primary outcomes analysed were the mean change in the levels of each carotenoid. The changes between the follow-up data and the baseline data for each participant were compared using paired $t$ tests and the general linear model function in SPSS version 19 (IBM). The analysis was based on completed observations. Outcomes were assessed by comparing the change between the pre-levels and the post-levels, which increased the likelihood of these outcomes being normally distributed and checked for normality before undertaking parametric analyses. The crude changes in biomarker levels and dietary outcomes are presented as means and 95\% CI using paired $t$ tests. These outcomes were adjusted by age, sex and community using a general linear model to account for differences due to age, sex or community. A $95 \%$ CI of the mean of the difference for each outcome that did not cross zero indicated a statistically significant difference. The effect of additional covariates in the statistical model was assessed, including total cholesterol and baseline values for biomarkers and baseline values for dietary outcomes. Based on previous studies, the sample size required to detect the expected mean changes of $10-50 \%$ in the levels of these carotenoids with a statistical significance level of $5 \%$ and power of $80 \%$ ranged from 9 for $\beta$-cryptoxanthin to 108 for lycopene ${ }^{(28,29)}$. Estimated sample sizes accounted for the family-level design effect, assuming an average family size of 2.6 with a family-level intra-class correlation coefficient of $0 \cdot 5^{(30)}$. Given the exploratory nature and hypothesis-generating intentions of the study, analyses were not adjusted for the design effect or for multiple comparisons. Not accounting for multiple comparisons was deemed to be justified on the basis of our intention to estimate the extent of changes in biomarker levels, consequent to the introduction of a fruit/vegetable intervention, rather than to formally test specific hypotheses as to whether changes occurred. Our statistical procedures reflect this focus on estimation rather than on hypothesis testing.

\section{Ethics}

The present study was conducted according to the guidelines laid down in the Declaration of Helsinki, and all procedures involving human subjects were approved by the human research ethics committees of the University of Melbourne, the University of South Australia and the Aboriginal Health and Medical Research Council (New South Wales). Community consent was obtained from the Boards of the three participating health services. The North Coast Area Health Service Research Ethics Committee approved the clinical audits of the participants' hospital records. Written informed consent was obtained from all subjects/parents or guardians.

\section{Results}

There were fifty-five Aboriginal families, which included 174 children, recruited to participate in the evaluation of the F\&V programme at the three Aboriginal Health Services. All assessments were of these children aged 0-17 years at baseline, with the majority of the children being aged between 3 and 12 years. The demographic characteristics of the 
Table 1. Baseline demographic characteristics of the participating children by individual community ( $n$ 174)

(Mean values and standard deviations; number of participants and percentages)

\begin{tabular}{|c|c|c|c|c|c|c|c|c|}
\hline & \multicolumn{2}{|c|}{$\begin{array}{l}\text { All com- } \\
\text { munities }\end{array}$} & \multicolumn{2}{|c|}{$\begin{array}{l}\text { Clar- } \\
\text { ence }\end{array}$} & \multicolumn{2}{|c|}{$\begin{array}{l}\text { Coffs } \\
\text { Harbour }\end{array}$} & \multicolumn{2}{|c|}{$\begin{array}{l}\text { Nam- } \\
\text { bucca }\end{array}$} \\
\hline & $n$ & $\%$ & $n$ & $\%$ & $n$ & $\%$ & $n$ & $\%$ \\
\hline Families & 55 & & 30 & & 12 & & 13 & \\
\hline Children & 174 & & 90 & & 36 & & 48 & \\
\hline \multicolumn{9}{|l|}{ Age (years) } \\
\hline Mean & \multicolumn{2}{|c|}{$7 \cdot 6$} & \multicolumn{2}{|c|}{7.5} & \multicolumn{2}{|c|}{11.0} & \multicolumn{2}{|c|}{$5 \cdot 8$} \\
\hline SD & \multicolumn{2}{|c|}{$4 \cdot 2$} & \multicolumn{2}{|c|}{$3 \cdot 8$} & \multicolumn{2}{|c|}{3.3} & \multicolumn{2}{|c|}{$4 \cdot 3$} \\
\hline \multicolumn{9}{|l|}{ Sex } \\
\hline Male & 82 & 47 & 46 & 51 & 18 & 50 & 18 & 37 \\
\hline Female & 92 & 53 & 44 & 49 & 18 & 50 & 30 & 63 \\
\hline $\begin{array}{l}\text { Children with } \\
\text { smoker(s) in } \\
\text { the household* }\end{array}$ & 107 & 66 & 62 & 69 & 18 & 50 & 27 & 71 \\
\hline $\begin{array}{l}\text { Families receiving } \\
\text { unemployment } \\
\text { benefits and } \\
\text { pensions }\end{array}$ & 51 & 93 & 28 & 93 & 10 & 83 & 13 & 100 \\
\hline
\end{tabular}

* Percentage of those with a valid response to smokers in the household.

participants at baseline are given in Table 1. As shown in Table 1, this was a cohort of low-income families with the majority receiving government benefits as their main source of income. The majority of adults in these households were smokers. There were differences between the cohorts of families at each location: the children were older and a small proportion of adults smoked in Coffs Harbour, while the children were younger and a greater proportion were female in the Nambucca Valley. However, the sample size at each location was not sufficient to examine the impact of these differences or differences in the implementation of the programme between the communities.

Of this cohort, 152 children had their blood samples taken (of which 142 were able to be analysed for nutritional biomarker levels), and 145 children completed dietary recalls at baseline. There were 115 children who had their blood samples taken both initially and at the 12-month follow-up, while 120 children completed dietary recalls at both time points. There were no significant differences in F\&V intake in those assessed only at baseline and those who underwent follow-up assessments (data not shown). Of the levels of nutritional biomarkers, only that of lutein-zeaxanthin was significantly lower among those who only provided a blood sample at baseline than among those who underwent follow-up assessments $(t=-2 \cdot 4, P=0 \cdot 018)$.

In the Clarence Valley and the Nambucca Valley, $70 \%$ of families (thirty of forty-three) collected $75 \%$ or more of available F\&V boxes during the follow-up period. These data were not available for Coffs Harbour.

\section{Impact of the fruit and vegetable programme on biomarker levels and fruit and vegetable intake}

The median period between baseline and follow-up assessments was $370 \mathrm{~d}$ (interquartile range $354-407 \mathrm{~d}$ ). In the overall sample of children, mean $\beta$-cryptoxanthin, lutein-zeaxanthin and vitamin $\mathrm{C}$ levels were significantly higher after participation in the $\mathrm{F} \& \mathrm{~V}$ programme for 12 months than the baseline levels (Table 2). These changes remained significant after adjustment for sex, age and community (Table 2). There were no significant changes in $\alpha$-tocopherol, $\gamma$-tocopherol or retinol levels. Adjustment for total cholesterol did not alter the mean change in the levels of carotenoids overall or in each community. Adjustment for the baseline level of biomarkers did not alter the mean changes in the levels carotenoids or vitamin C overall. There were no significant differences in biomarker levels by sex at baseline, although girls did show a greater mean change in $\beta$-cryptoxanthin levels than boys at follow-up (girls: $43.6 \mathrm{nmol} / 1$; boys: $2.4 \mathrm{nmol} / 1, F=3.43, P=0.07)$. The use of vitamin and mineral supplements was reported by $13 \%$ of the children at baseline and $9 \%$ of the children at the follow-up assessments. The pattern of changes in biomarker levels was similar, except that the increase in $\beta$-cryptoxanthin level was not statistically significant, after excluding those participants who reported supplement use at follow-up.

At baseline, the $\mathrm{F} \& \mathrm{~V}$ programme participants (and/or carers) reported that the children's mean intake of fruit was

Table 2. Plasma biomarker levels of the participating children $(n 115)$ before and after the fruit and vegetable programme

(Mean values and standard deviations; mean differences and $95 \%$ confidence intervals)

\begin{tabular}{|c|c|c|c|c|c|c|c|c|}
\hline & \multicolumn{2}{|c|}{ Before (nmol/l) } & \multicolumn{2}{|c|}{ After (nmol/l) } & \multirow{2}{*}{$\begin{array}{c}\text { Mean difference } \dagger \\
(\mathrm{nmol} / \mathrm{l})\end{array}$} & \multirow[b]{2}{*}{$95 \% \mathrm{Cl}$} & \multirow{2}{*}{$\begin{array}{c}\text { Adjusted mean } \\
\text { difference } \neq(\mathrm{nmol} / \mathrm{l})\end{array}$} & \multirow[b]{2}{*}{$95 \% \mathrm{Cl}$} \\
\hline & Mean & SD & Mean & SD & & & & \\
\hline$\beta$-Carotene & 346.6 & 173.0 & 338.9 & 195.4 & -7.7 & $-39.5,24.0$ & $-12 \cdot 2$ & $-48 \cdot 4,24 \cdot 1$ \\
\hline$\alpha$-Carotene & $66 \cdot 1$ & $56 \cdot 7$ & 73.7 & $53 \cdot 3$ & $7 \cdot 6$ & $-2 \cdot 1,17 \cdot 3$ & $4 \cdot 3$ & $-6 \cdot 7,15 \cdot 2$ \\
\hline Lycopene & $637 \cdot 7$ & 306.5 & $586 \cdot 9$ & $295 \cdot 1$ & -50.9 & $-106 \cdot 8,5 \cdot 1$ & $-42 \cdot 9$ & $-104 \cdot 1,18 \cdot 3$ \\
\hline$\beta$-Cryptoxanthin & 159.0 & $167 \cdot 2$ & 183.9 & $167 \cdot 0$ & $25 \cdot 0^{*}$ & $2 \cdot 9,47 \cdot 1$ & $28.9^{*}$ & $4 \cdot 2,53 \cdot 6$ \\
\hline Lutein-zeaxanthin & 303.3 & 163.5 & $337 \cdot 8$ & $170 \cdot 4$ & $34 \cdot 5^{\star}$ & $4 \cdot 3,64 \cdot 6$ & $39 \cdot 3^{*}$ & $6 \cdot 2,72 \cdot 5$ \\
\hline Vitamin C $(n 57)(\mu \mathrm{mol} / \mathrm{l})$ & $49 \cdot 1$ & 21.4 & 59.6 & 24.6 & $10 \cdot 5^{\star}$ & $2 \cdot 3,18 \cdot 7$ & $10 \cdot 1^{*}$ & $2 \cdot 0,18 \cdot 1$ \\
\hline$\alpha$-Tocopherol $(\mu \mathrm{mol} / \mathrm{l})$ & $23 \cdot 6$ & $5 \cdot 3$ & $23 \cdot 2$ & 4.9 & -0.4 & $-1.3,0.5$ & -0.4 & $-1.4,0.7$ \\
\hline$\gamma$-Tocopherol $(\mu \mathrm{mol} / \mathrm{l})$ & 2.4 & $1 \cdot 2$ & $2 \cdot 2$ & $1 \cdot 1$ & -0.2 & $-0.4,0.1$ & -0.1 & $-0.4,0.2$ \\
\hline Retinol ( $\mu \mathrm{mol} / \mathrm{l})$ & $2 \cdot 1$ & 0.7 & $2 \cdot 1$ & 0.7 & 0.1 & $-0.1,0.2$ & 0.0 & $-0.1,0.2$ \\
\hline
\end{tabular}

*Values were significantly different from zero $(P<0.05)$

† Unadjusted mean difference (after-before), paired $t$ test.

$\ddagger$ Adjusted for sex, age and community using the general linear model (univariate ANOVA). 
Table 3. Fruit and vegetable intake of the participating children $(n 121)$ before and after the fruit and vegetable programme

(Mean values and standard deviations; mean differences and $95 \%$ confidence intervals)

\begin{tabular}{|c|c|c|c|c|c|c|c|c|}
\hline & \multicolumn{4}{|c|}{ Servings/d } & \multirow[b]{3}{*}{ Mean difference $†$} & \multirow[b]{3}{*}{$95 \% \mathrm{Cl}$} & \multirow[b]{3}{*}{$\begin{array}{c}\text { Adjusted mean } \\
\text { difference } \neq\end{array}$} & \multirow[b]{3}{*}{$95 \% \mathrm{Cl}$} \\
\hline & \multicolumn{2}{|c|}{ Before } & \multicolumn{2}{|c|}{ After } & & & & \\
\hline & Mean & SD & Mean & SD & & & & \\
\hline \multicolumn{9}{|l|}{$24 \mathrm{~h}$ dietary recall } \\
\hline Fruit & 1.0 & 1.4 & 1.0 & $1 \cdot 1$ & -0.03 & $-0.30,0.24$ & $-0 \cdot 10$ & $-0.42,0.23$ \\
\hline Vegetables & 0.6 & 0.9 & 0.5 & 0.8 & -0.09 & $-0.31,0.14$ & -0.13 & $-0.40,0.15$ \\
\hline Vegetables (including potato) & 0.8 & 1.2 & 0.7 & 0.9 & -0.15 & $-0.42,0.12$ & -0.20 & $-0.53,0.12$ \\
\hline Fruit and vegetables & 1.8 & 1.8 & 1.6 & 1.6 & -0.18 & $-0.56,0.20$ & -0.30 & $-0.76,0.15$ \\
\hline \multicolumn{9}{|l|}{ Short questions§ } \\
\hline Fruit $(n 111)$ & $2 \cdot 2$ & 1.0 & 2.5 & 1.4 & $0.23^{*}$ & $0.004,0.46$ & 0.11 & $-0.18,0.39$ \\
\hline Vegetables $(n 118)$ & 2.5 & 1.4 & $2 \cdot 2$ & $1 \cdot 1$ & -0.27 & $-0.54,0.00$ & $-0.49^{\star}$ & $-0.82,-0.16$ \\
\hline
\end{tabular}

${ }^{*}$ Values were significantly different from zero $(P<0.05)$

$\dagger$ Unadjusted mean difference (after-before), paired $t$ test.

$\ddagger$ Adjusted for sex, age and community using the general linear model (univariate ANOVA)

$\S$ Questions about average servings of fruit and vegetables consumed, asked at the time of the $24 \mathrm{~h}$ dietary recall.

$1 \cdot 0$ servings/d and that of vegetables (excluding deep-fried potato) was 0.8 servings/d in the $24 \mathrm{~h}$ dietary recalls, but their mean intake of fruit was $2 \cdot 2$ servings/d and that of vegetables was 2.5 servings/d in response to the short questions posed simultaneously (Table 3 ). There were no significant changes in $\mathrm{F} \& \mathrm{~V}$ intake reported using $24 \mathrm{~h}$ dietary recalls for the overall sample in either the crude analysis (Table 3) or after adjustment for sex, age and community (Table 3). However, there was a small but statistically significant increase in fruit intake observed during the crude analysis, and a small, but statistically significant, decrease in vegetable intake was reported using short questions in the crude analysis (Table 3) and after adjusting for sex, age and community (Table 3 ).

At follow-up, the participants or parents reported receiving their last F\&V box $1 \mathrm{~d}$ to 4 weeks earlier. Analysis of these data showed that 100 children had received a box within the $7 \mathrm{~d}$ before the $24 \mathrm{~h}$ recall at follow-up, and of these, eighty-three had biomarkers at baseline and follow-up and eighty-six had $24 \mathrm{~h}$ dietary recalls at baseline and follow-up. On including only these data, no substantial differences were observed in the pattern of changes in the biomarker levels or self-reported $\mathrm{F} \& \mathrm{~V}$ intake, except that the increases in $\beta$-cryptoxanthin and lutein-zeaxanthin levels were not statistically significant and the decrease in lycopene level was statistically significant after adjustment for age, sex and community.

On the whole, there were few differences of clinical import in response profiles between the communities, notwithstanding some statistically significant variations that were accounted for in multivariable-adjusted analyses of pooled data ${ }^{(31)}$.

\section{Changes in macronutrient intake}

There was a decrease in the self-reported macronutrient intake in the follow-up dietary recalls than at baseline, particularly of carbohydrates and total sugars (Supplementary file 2, available online). The mean total energy intake at baseline was 7570 (SD 3156) kJ, while at follow-up, it was 6482 (sD 2197) kJ. To facilitate comparison with the large variation in intake among these children aged $0-17$ years, macronutrient intake per MJ was also analysed. In the analysis of macronutrient intake per $\mathrm{MJ}$, there were small but statistically significant decreases in total sugar $(1.6 \mathrm{~g} / \mathrm{MJ})$ and added sugar $(1.2 \mathrm{~g} / \mathrm{MJ})$ intake, while the intake of other macronutrients was unchanged (Table 4). However, after adjustment for sex, age and

Table 4. Change in macronutrient density ( $/ \mathrm{MJ})$ among the participants aged $0-17$ years $(n 121)$ before and after the fruit and vegetable programme (Mean values and standard deviations; mean differences and $95 \%$ confidence intervals)

\begin{tabular}{|c|c|c|c|c|c|c|c|c|}
\hline \multirow[b]{2}{*}{ Macronutrients $†$} & \multicolumn{2}{|c|}{ Before } & \multicolumn{2}{|c|}{ After } & \multirow[b]{2}{*}{ Mean difference $\ddagger$} & \multirow[b]{2}{*}{$95 \% \mathrm{Cl}$} & \multirow[b]{2}{*}{ Adjusted mean difference§ } & \multirow[b]{2}{*}{$95 \% \mathrm{Cl}$} \\
\hline & Mean & SD & Mean & SD & & & & \\
\hline Protein & $8 \cdot 2$ & $2 \cdot 8$ & 8.5 & $2 \cdot 7$ & 0.2 & $-0.4,0.9$ & 0.1 & $-0.6,0.9$ \\
\hline Total fat & 8.9 & 1.6 & $9 \cdot 3$ & 1.5 & 0.4 & $-0.01,0.8$ & 0.5 & $0.1,0.9$ \\
\hline Saturated fat & $4 \cdot 1$ & $1 \cdot 2$ & $4 \cdot 2$ & $1 \cdot 0$ & 0.02 & $-0.2,0.3$ & 0.2 & $-0.1,0.4$ \\
\hline $\mathrm{CHO}$ & $30 \cdot 7$ & 4.8 & $29 \cdot 6$ & 4.8 & $-1 \cdot 1$ & $-2 \cdot 2,0.02$ & $-1 \cdot 2$ & $-2 \cdot 5,0 \cdot 1$ \\
\hline Total sugar & $14 \cdot 7$ & $5 \cdot 6$ & $13 \cdot 1$ & $5 \cdot 2$ & $-1 \cdot 6^{\star}$ & $-2 \cdot 8,-0.4$ & $-1 \cdot 0$ & $-2 \cdot 4,0.4$ \\
\hline Added sugar & $10 \cdot 6$ & 5.9 & 9.4 & $5 \cdot 2$ & $-1 \cdot 2^{\star}$ & $-2.4,-0.001$ & 0.03 & $-1.4,1.5$ \\
\hline Starch & $15 \cdot 8$ & 4.4 & $16 \cdot 3$ & $4 \cdot 7$ & 0.5 & $-0.7,1 \cdot 6$ & -0.2 & $-1 \cdot 6,1 \cdot 2$ \\
\hline
\end{tabular}

$\mathrm{CHO}$, carbohydrate.

${ }^{*}$ Values were significantly different from zero $(P<0.05)$

$\dagger$ Alcohol intake was not reported in any $24 \mathrm{~h}$ dietary recall.

$\ddagger$ Unadjusted mean difference (after-before), paired $t$ test.

$\S$ Adjusted for sex, age and community using the general linear model (univariate ANOVA). 
community, there were no significant changes in the intake of any of the macronutrients per MJ overall (Table 4).

\section{Discussion}

The major findings of the present study of the impact of subsidised fresh F\&V provided by three local Aboriginal community-controlled health services to disadvantaged Aboriginal families in rural communities were the significant increases in the levels of biomarkers of F\&V intake including $\beta$-cryptoxanthin, vitamin $\mathrm{C}$ and lutein-zeaxanthin. In contrast to the changes in biomarker levels, there were no changes in the self-reported intake of F\&V (when using either the $24 \mathrm{~h}$ dietary recall or the short dietary questions on usual intake). Furthermore, self-reported 'usual intake' was considerably higher than that reported in the $24 \mathrm{~h}$ dietary recalls.

These findings highlighted the well-known limitations of the self-reported dietary intake ${ }^{(32)}$ and the role of biomarkers as alternative more objective measures of $\mathrm{F} \& \mathrm{~V}$ intake ${ }^{(33)}$. Collecting self-reported dietary intake data is particularly challenging for children, as the dietary intake data are collected with inputs from both a parent/carer and a child, which may lead to a different likelihood of bias due to difficulties with the estimation of quantities and under-reporting ${ }^{(34)}$. The decrease in self-reported energy intake at the 12-month follow-up (which would be expected to increase slightly in children) suggested that repeated self-reported dietary intake measurements may be susceptible to reporting bias in assessing the impact of nutrition interventions ${ }^{(35)}$. The present study has also shown that it is feasible to obtain blood samples for the measurement of biomarker levels from children in a community-based intervention study with appropriate community engagement.

The baseline carotenoid levels in the present study were similar, except for lycopene level, which was higher, to those reported in a representative sample of 4231 American children aged $6-16$ years $^{(36)}$, and $\beta$-carotene level was also similar to that reported in 467 Australian preschool-aged children $^{(37)}$. While no comparable published data were obtained in Australian children, Hodge et $a l .{ }^{(38)}$ found that Indigenous Australian adults have lower carotenoid levels than nonIndigenous Australians. These data are consistent with the finding that most children in high-income countries do not consume the recommended levels of $F \& V^{(39-42)}$

The changes in vitamin $C, \beta$-cryptoxanthin and lutein-zeaxanthin levels were consistent with an increase in F\&V intake. This pattern of changes suggests that fruit intake may have increased more than vegetable intake ${ }^{(33,43,44)}$, although the self-reported data could not confirm this. Vitamin C level increased by $10 \mu \mathrm{mol} / 1$ (21\%). Khaw et al. ${ }^{(45)}$ reported that each quintile of plasma vitamin C (10-20 $\mathrm{mol} / \mathrm{l})$ was associated with a $20-50 \mathrm{~g}$ increase in fruit equivalent to half an apple or orange (and 10-20 g increase in vegetables) in a large prospective study in adults. The $18 \%$ increase in $\beta$-cryptoxanthin level is consistent with an increased intake of orange/red F\&V, particularly of citrus fruit ${ }^{(46)}$. Lutein-zeaxanthin, the level of which increased by $11 \%$, is commonly found in green leafy vegetables, pumpkins, beans and maize, all of which are commonly included in communal meals consumed in contemporary Aboriginal communities ${ }^{(29)}$. The level of $\beta$-carotene, which is widely distributed in many $\mathrm{F} \& \mathrm{~V}$, did not change in the present study. This may reflect the more limited bioavailability of $\beta$-carotene compared with the other carotenoids ${ }^{(44,47)}$.

The findings of the present study are consistent with a recent systematic review of the role of biomarkers in $F \& V$ intervention studies, which found significant increases in the levels of one or more biomarkers in thirty-five of the thirtysix F\&V provision studies and fourteen of the sixteen nutrition counselling studies, most commonly in those of $\beta$-carotene, vitamin $C, \alpha$-carotene and lutein ${ }^{(33)}$. The proportional increases in $\beta$-cryptoxanthin, vitamin $C$ and lutein-zeaxanthin levels observed in the present study were mostly greater than those reported in a nutrition counselling $\mathrm{RCT}^{(48)}$ in which selfreported $\mathrm{F} \& \mathrm{~V}$ intake increased by 1.4 servings/d but less than those in a food provision RCT in which the consumption of $500 \mathrm{~g}$ of $\mathrm{F} \& \mathrm{~V}$ per d was compared with that of $100 \mathrm{~g}$ of $\mathrm{F} \& \mathrm{~V}$ per $\mathrm{d}^{(49)}$. Thus, carotenoids and vitamin $\mathrm{C}$ are responsive to changes in $\mathrm{F} \& \mathrm{~V}$ intake ${ }^{(33)}$, although further work is needed to confirm the linear dose-response relationship between F\&V intake and the levels of these biomarkers, particularly of carotenoids.

Although the increases in carotenoid and vitamin C levels in the present study appear to be consistent with an increase in $\mathrm{F} \& \mathrm{~V}$ of one to two servings/d, the self-reported dietary intake data do not confirm this. However, targeted F\&V subsidies, as additions to national food subsidy programmes or as standalone interventions, have been shown to increase $\mathrm{F} \& \mathrm{~V}$ intake by one to two servings/d or $20-30 \%$ in women during pregnancy ${ }^{(50)}$ and other life stages ${ }^{(51,52)}$. There is limited evidence for families or children specifically. Increased intake of $\mathrm{F} \& \mathrm{~V}$ of this magnitude is sufficient to improve long-term health outcomes, such as reducing the incidence of IHD or type 2 diabetes $^{(1,3,6,53,54)}$.

The key question is whether the short-term benefits of healthy food subsidies will translate to sustainable improvements in nutrition. There is evidence of healthier dietary intake or food purchases persisting, although attenuated, for 6 months after participation in food subsidy programmes ${ }^{(20,51)}$. However, this was not noted in later followup of children whose families had previously participated in the Special Supplemental Nutrition Program for Women, Infants and Children in the USA ${ }^{(55)}$. The evidence that price discounts are more effective at changing dietary behaviour than other strategies ${ }^{(20)}$ and that price discounts or increases are projected to have a larger impact on low-income individuals or families ${ }^{(17,18)}$ is important. Given the consistent association between less healthy dietary behaviour and lower socio-economic status ${ }^{(56)}$, it is likely that a range of complementary strategies will be needed to improve nutritional status among the most disadvantaged. It is unclear whether the nutritional challenges among Indigenous Australians who live in non-remote areas are different from those among other disadvantaged families in high-income countries. It is clear though that Indigenous Australians have much earlier onset and higher rates of chronic diseases ${ }^{(57)}$ and 
thus have the most to gain from strategies that increase $F \& V$ intake.

An obvious limitation of the present study was the lack of a control group. This would have been difficult to implement given the clear economic benefit of the F\&V subsidy, irrespective of any nutritional or health impacts that were the focus of the present study. However, a control group was contemplated as an equitable way to manage the waiting list of eligible families for this programme, but was ultimately considered impractical given the limited local research capacity in a busy Aboriginal community-controlled health service ${ }^{(58)}$. Regression to the mean and physiological changes with age was addressed in the analysis by including age and baseline levels as covariates in the model. Another limitation of the present study was that the impact of the F\&V subsidies could not be separated from that of other elements of the programme, including nutrition education and increased engagement with Aboriginal primary health care services. However, other studies have suggested that the benefits of this programme are likely to be primarily due to the F\&V subsidies ${ }^{(14,20,50)}$.

The use of non-fasting blood specimens was a potential source of error as serum vitamin $C$ and $\alpha$ - and $\beta$-carotene levels have been shown to increase acutely several hours post-ingestion of carotene- or ascorbate-rich foods ${ }^{(59,60)}$. However, it was considered impractical to expect these children to arrive fasted for these assessments. In addition, the biological half-life of the serum carotenoids ranges from $26 \mathrm{~d}$ for lycopene to $76 \mathrm{~d}$ for lutein ${ }^{(61)}$, while the biological halflife of vitamin $C$ is $10-20 \mathrm{~d}^{(62)}$, which suggests that the serum levels reflect intake in the previous several weeks, provided intake is relatively consistent. Thus, the significant increases in $\beta$-cryptoxanthin, lutein-zeaxanthin and vitamin $\mathrm{C}$ levels are likely to represent medium-term F\&V intake, although the serum levels could have been influenced by recent ingestion of $\mathrm{F} \& \mathrm{~V}$, particularly vitamin $\mathrm{C}$ level by supplements or vitamin C-fortified foods.

The findings of this evaluation study of the nutritional improvements associated with $F \& V$ subsidies suggest that there is a need for a controlled study to verify these conclusions. Higher-quality longitudinal data would also provide the opportunity for an economic analysis that could also inform decisions about investing in food subsidies. The validity of biomarkers as indicators of F\&V intake is well established in adults ${ }^{(33)}$. International studies have established the normal range of plasma carotenoid concentrations in children $^{(36,37,63-65)}$. However, further studies are needed to confirm their validity and practicality as measures of $F \& V$ intake in interventions involving children. This is important given the discrepancies between self-reported dietary intake and biomarker levels observed in the present study.

The potential reduction in chronic disease risk due to increased F\&V intake suggests that it would also be useful to assess the nutritional status of adults in family-focused nutrition intervention studies, given the long time lag between improving $\mathrm{F} \& \mathrm{~V}$ intake in children and any manifestation of chronic diseases. Increased $\mathrm{F} \& \mathrm{~V}$ intake is perhaps more likely to be sustained if it involves both adults and children in families. The sustainability of any change in F\&V intake underpins any long-term health impacts. This programme provided a heavily subsidised supply of fresh F\&V to these families, sufficient to meet the requirements of a family of five, which may be necessary to engage the most disadvantaged families. However, it would be useful to trial the impacts on dietary intake or nutritional status of $F \& V$ programmes that include lesser value subsidies or a larger participant contribution.

In conclusion, F\&V subsidies improve the nutritional status of disadvantaged Indigenous Australian children. The measurement of plasma carotenoid and vitamin $\mathrm{C}$ levels as biomarkers are feasible to measure $\mathrm{F} \& \mathrm{~V}$ intake in these children and may offer an objective alternative to self-reported dietary intake. Improving the F\&V intake of these children is challenging and emphasises the need to link any subsidies with effective nutrition education to promote meal planning and preparation skills. The delivery of F\&V subsidies in a community health setting strengthens the link between preventive health activities and improved nutrition. A controlled study of subsidised healthy foods is warranted to investigate the costeffectiveness of this strategy to improve both the nutrition and health of the most disadvantaged families.

\section{Supplementary material}

To view supplementary material for this article, please visit http://dx.doi.org/10.1017/S0007114513001700

\section{Acknowledgements}

We acknowledge the families who participated in this evaluation study and the staff at the three health services, particularly David Ferguson and May Robinson from the Bulgarr fruit and vegetable committee, for the success of the F\&V programme. Kerry Hampshire, Fiona Smith, Karen Spark, Nicole Turner, Lea Clayden and Marie Gough contributed significantly to the clinical assessments and data collection. Dr Karen Walker and Ms Jiang Hwa Lee at Monash University entered dietary recall data into FoodWorks and produced standard and supplementary nutrient and food intake analyses. The present study was supported by the National Health and Medical Research Council, Australia (PhD scholarship ID no. 520681 and program grant no. 320860). The authors' contributions are as follows: A. P. B., H. V., P. M. and K. O. designed the research; A. P. B. conducted the research; A. P. B., M. D., A. E., H. V. and K. O. analysed the data; A. P. B., H. V., P. M. and K. O. wrote the paper; A. P. B. had primary responsibility for the final content; C. S. K. undertook the analysis of carotenoids. All authors read and approved the final manuscript. None of the authors has a conflict of interest.

\section{References}

1. Crowe FL, Roddam AW, Key TJ, et al. (2011) Fruit and vegetable intake and mortality from ischaemic heart disease: results from the European Prospective Investigation into Cancer and Nutrition (EPIC)-Heart study. Eur Heart $J 32$ $1235-1243$. 
2. Hung H-C, Joshipura KJ, Jiang R, et al. (2004) Fruit and vegetable intake and risk of major chronic disease. J Natl Cancer Inst 96, 1577-1584.

3. Bazzano LA, Serdula M \& Liu S (2005) Prevention of type 2 diabetes by diet and lifestyle modification. J Am Coll Nutr 24, 310-319.

4. He FJ, Nowson CA \& MacGregor GA (2006) Fruit and vegetable consumption and stroke: meta-analysis of cohort studies. Lancet 367, 320-326.

5. Joshipura KJ, Ascherio A, Manson JE, et al. (1999) Fruit and vegetable intake in relation to risk of ischemic stroke. JAMA 282, 1233-1239.

6. World Cancer Research Fund Expert Panel (2007) Food, Nutrition, Physical Activity and the Prevention of Cancer: A Global Perspective. Second Expert Report. Los Angeles: World Cancer Research Fund and American Institute for Cancer Research.

7. Rolls BJ, Ello-Martin JA \& Tohill BC (2004) What can intervention studies tell us about the relationship between fruit and vegetable consumption and weight management? Nutr $\operatorname{Rev}$ 62, 1-17.

8. Appel LJ, Moore TJ, Obarzanek E, et al. (1997) A clinical trial of the effects of dietary patterns on blood pressure. DASH Collaborative Research Group. $N$ Engl J Med 336, 1117-1124.

9. Hall JN, Moore S, Harper SB, et al. (2009) Global variability in fruit and vegetable consumption. Am J Prev Med 36, 402-409.e5.

10. Giskes K, Turrell G, Patterson C, et al. (2002) Socio-economic differences in fruit and vegetable consumption among Australian adolescents and adults. Public Health Nutr 5, 663-669.

11. Dubowitz T, Heron M, Bird CE, et al. (2008) Neighborhood socioeconomic status and fruit and vegetable intake among whites, blacks, and Mexican Americans in the United States. Am J Clin Nutr 87, 1883-1891.

12. Dehghan M, Akhtar-Danesh N \& Merchant AT (2011) Factors associated with fruit and vegetable consumption among adults. J Hum Nutr Diet 24, 128-134.

13. Lock K, Pomerleau J, Causer L, et al. (2005) The global burden of disease attributable to low consumption of fruit and vegetables: implications for the global strategy on diet. Bull World Health Organ 83, 100-108.

14. Cobiac LJ, Vos T \& Veerman JL (2010) Cost-effectiveness of interventions to promote fruit and vegetable consumption. PLoS One 5, e14148.

15. Sassi F, Cecchini M, Lauer J, et al. (2009) Improving Lifestyles, Tackling Obesity: The Health and Economic Impact of Prevention Strategies. OECD Health Working Papers, no. 48. Paris: OECD Publishing.

16. Jensen JD \& Smed S (2007) Cost-effective design of economic instruments in nutrition policy. Int J Behav Nutr Phys Act 4, 10.

17. Smed S, Jensen JD \& Denver S (2007) Socio-economic characteristics and the effect of taxation as a health policy instrument. Food Policy 32, 624-639.

18. Powell LM \& Chaloupka FJ (2009) Food prices and obesity: evidence and policy implications for taxes and subsidies. Milbank Q 87, 229-257.

19. D'Souza L, Renfrew M, McCormick F, et al. (2006) Food-support Programmes for Low-income and Socially Disadvantaged Childbearing Women in Developed Countries - Systematic Review of the Evidence. London: National Institute for Health and Clinical Excellence.

20. Ni Mhurchu C, Blakely T, Jiang Y, et al. (2010) Effects of price discounts and tailored nutrition education on supermarket purchases: a randomized controlled trial. $A m \mathrm{~J}$ Clin Nutr 91, 736-747.

21. Ball K, McNaughton S, Mhurchu C, et al. (2011) Supermarket Healthy Eating for Life (SHELf): protocol of a randomised controlled trial promoting healthy food and beverage consumption through price reduction and skill-building strategies. BMC Public Health 11, 715.

22. Australian Bureau of Statistics (2010) 4704.0 - The Health and Welfare of Australia's Aboriginal and Torres Strait Islander Peoples, Oct 2010. Canberra: Commonwealth of Australia, Australian Bureau of Statistics.

23. Jones R \& Smith F (2006) Are there health benefits from improving basic nutrition in a remote Aboriginal community? Aust Fam Physician 35, 453-454.

24. Jones R \& Smith F (2007) Fighting disease with fruit. Aust Fam Physician 36, 863-864.

25. McLennan W \& Podger A (1998) National Nutrition Survey User's Guide, 1995. Canberra: Australian Bureau of Statistics and Commonwealth Department of Health and Family Services.

26. Flood Vicki, Webb Karen \& Rangan Anna (2005) Recommendations for Short Questions to Assess Food Consumption in Children for the NSW Health Surveys. Sydney: NSW Centre for Public Health Nutrition.

27. Su Q, Rowley KG \& O'Dea K (1999) Stability of individual carotenoids, retinol and tocopherols in human plasma during exposure to light and after extraction. J Chromatogr B Biomed Sci Appl 729, 191-198.

28. Rose D, Habicht JP \& Devaney B (1998) Household participation in the Food Stamp and WIC programs increases the nutrient intakes of preschool children. J Nutr 128, 548-555.

29. Rowley KG, Su Q, Cincotta M, et al. (2001) Improvements in circulating cholesterol, antioxidants, and homocysteine after dietary intervention in an Australian Aboriginal community. Am J Clin Nutr 74, 442-448.

30. Metcalf PA, Scragg RKR, Stewart AW, et al. (2007) Design effects associated with dietary nutrient intakes from a clustered design of 1 to 14-year-old children. Eur J Clin Nutr 61, 1064-1071.

31. Black AP (2012) The Impact of Food Subsidy Programs on the Health of Disadvantaged Populations. An Evaluation of Subsidised Fruit and Vegetables in a Rural Aboriginal Medical Service [PhD]. Adelaide: University of South Australia.

32. Bingham S (2007) Dietary assessment. In Essentials of Human Nutrition, 3rd ed. [J Mann and AS Truswell, editors]. Oxford: Oxford University Press.

33. Baldrick FR, Woodside JV, Elborn JS, et al. (2011) Biomarkers of fruit and vegetable intake in human intervention studies: a systematic review. Crit Rev Food Sci Nutr 51, 795-815.

34. Livingstone MBE, Robson PJ \& Wallace JMW (2004) Issues in dietary intake assessment of children and adolescents. $\mathrm{BrJ}$ Nutr 92, Suppl. 2, S213-S222.

35. Natarajan L, Pu M, Fan J, et al. (2010) Measurement error of dietary self-report in intervention trials. Am J Epidemiol 172, 819-827.

36. Ford ES, Gillespie C, Ballew C, et al. (2002) Serum carotenoid concentrations in US children and adolescents. Am J Clin Nutr 76, 818-827.

37. Karr M, Mira M, Causer J, et al. (1997) Plasma and serum micronutrient concentrations in preschool children. Acta Paediatr 86, 677-682.

38. Hodge A, Cunningham J, Maple-Brown L, et al. (2011) Plasma carotenoids are associated with socioeconomic status in an urban Indigenous population: an observational study. BMC Public Health 11, 76. 
39. Heath DL \& Panaretto KS (2005) Nutrition status of primary school children in Townsville. Aust J Rural Health 13, 282-289.

40. Gwynn J, Flood V, D'Este C, et al. (2012) Poor food and nutrient intake among Indigenous and non-Indigenous rural Australian children. BMC Pediatr 12, 12.

41. CSIRO Preventative Health National Research Flagship, University of South Australia (2007) 2007 Australian National Children's Nutrition and Physical Activity Survey - Main Findings. Canberra: Department of Health and Ageing.

42. Lorson BA, Melgar-Quinonez HR \& Taylor CA (2009) Correlates of fruit and vegetable intakes in US children. J Am Diet Assoc 109, 474-478.

43. Dauchet L, Peneau S, Bertrais S, et al. (2008) Relationships between different types of fruit and vegetable consumption and serum concentrations of antioxidant vitamins. $\mathrm{Br} J$ Nutr 100, 633-641.

44. Burri BJ, Chang JST \& Neidlinger TR (2011) $\beta$-Cryptoxanthinand $\alpha$-carotene-rich foods have greater apparent bioavailability than $\beta$-carotene-rich foods in Western diets. $\mathrm{Br} J$ Nutr 105, 212-219.

45. Khaw KT, Bingham S, Welch A, et al. (2001) Relation between plasma ascorbic acid and mortality in men and women in EPIC-Norfolk prospective study: a prospective population study. European Prospective Investigation into Cancer and Nutrition. Lancet 357, 657-663.

46. Agricultural Research Service. (2010) SR24 - Reports by Single Nutrients. Washington, DC: United States Department of Agriculture. http://www.ars.usda.gov/Services/docs. htm?docid=22114 (updated 28 September 2010).

47. van het Hof KH, Brouwer IA, West CE, et al. (1999) Bioavailability of lutein from vegetables is 5 times higher than that of beta-carotene. Am J Clin Nutr 70, 261-268.

48. John JH, Ziebland S, Yudkin P, et al. (2002) Effects of fruit and vegetable consumption on plasma antioxidant concentrations and blood pressure: a randomised controlled trial. Lancet 359, 1969-1974.

49. Broekmans WMR, Klopping-Ketelaars IAA, Schuurman C, et al. (2000) Fruits and vegetables increase plasma carotenoids and vitamins and decrease homocysteine in humans. J Nutr 130, 1578-1583.

50. Burr ML, Trembeth J, Jones KB, et al. (2007) The effects of dietary advice and vouchers on the intake of fruit and fruit juice by pregnant women in a deprived area: a controlled trial. Public Health Nutr 10, 559-565.

51. Herman DR, Harrison GG, Afifi AA, et al. (2008) Effect of a targeted subsidy on intake of fruits and vegetables among low-income women in the special supplemental nutrition program for women, infants, and children. Am J Public Health 98, 98-105.
52. Kennedy BM, Champagne CM, Ryan DH, et al. (2009) The "Rolling Store:" an economical and environmental approach to the prevention of weight gain in African American women. Ethn Dis 19, 7-12.

53. He FJ, Nowson CA, Lucas M, et al. (2007) Increased consumption of fruit and vegetables is related to a reduced risk of coronary heart disease: meta-analysis of cohort studies. J Hum Hypertens 21, 717-728.

54. Carter P, Gray LJ, Troughton J, et al. (2010) Fruit and vegetable intake and incidence of type 2 diabetes mellitus: systematic review and meta-analysis. BMJ 341, c4229.

55. Rush D, Leighton J, Sloan NL, et al. (1988) The National WIC Evaluation: evaluation of the Special Supplemental Food Program for Women, Infants, and Children. VI. Study of infants and children. Am J Clin Nutr 48, Suppl. 2, 484-511.

56. Marmot M, Friel S, Bell R, et al. (2008) Closing the gap in a generation: health equity through action on the social determinants of health. Lancet 372, 1661-1669.

57. Australian Bureau of Statistics (2011) 4704.0 The Health and Welfare of Australia's Aboriginal and Torres Strait Islander Peoples, 2010. Mortality Data Cubes. Canberra: Commonwealth of Australia.

58. Sibthorpe BM, Bailie RS, Brady MA, et al. (2002) The demise of a planned randomised controlled trial in an urban Aboriginal medical service. Med J Aust 176, 273-276.

59. Jensen CD, Spiller GA, Pattison TS, et al. (1986) Acute effects of dietary carotenes on serum alpha and beta carotene in humans. Nutr Rep Int 33, 117-122.

60. Sánchez-Moreno C, Cano MP, de Ancos B, et al. (2003) Effect of orange juice intake on vitamin $\mathrm{C}$ concentrations and biomarkers of antioxidant status in humans. Am J Clin Nutr $\mathbf{7 8}$, 454-460.

61. Burri BJ, Neidlinger TR \& Clifford AJ (2001) Serum carotenoid depletion follows first-order kinetics in healthy adult women fed naturally low carotenoid diets. J Nutr 131, 2096-2100.

62. Naidu KA (2003) Vitamin C in human health and disease is still a mystery? An overview. Nutr J 2, 7.

63. Brady H, Lamb MM, Sokol RJ, et al. (2007) Plasma micronutrients are associated with dietary intake and environmental tobacco smoke exposure in a paediatric population. Public Health Nutr 10, 712-718.

64. Lenhartz H, Schweitzer R, Botticher D, et al. (1997) Plasma carotenoids in German children and adolescents. Eur $J$ Pediatr 156, 71-73.

65. Malvy DJ, Burtschy B, Dostalova L, et al. (1993) Serum retinol, beta-carotene, alpha-tocopherol and cholesterol in healthy French children. Int J Epidemiol 22, 237-246. 